\title{
Proposal for an augmentative and alternative communication conversational analysis protocol
}

\author{
Proposta de um protocolo de análise conversacional \\ de comunicação suplementar e alternativa
}

Carla Ciceri Cesa ${ }^{(1)}$

Helena Bolli Mota(2)

Lenisa Brandão(3)

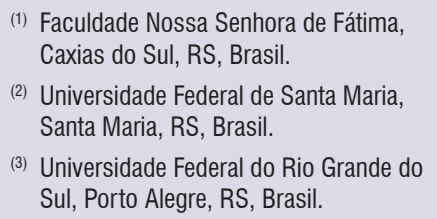

(3) Universidade Federal do Rio Grande do Sul, Porto Alegre, RS, Brasil.

Conflict of interest: non-existent

Received on: May 08, 2017

Accepted on: July 18, 2017

Mailing address:

Carla Ciceri Cesa

Rua Alexandre Fleming, 454 - Madureira Caxias do Sul, Rio Grande do Sul, Brasil CEP: 95041-520

E-mail: carlacesafga@yahoo.com.br

\section{ABSTRACT}

Purpose: to propose an assessment of communication that includes the conversational analysis of children who have cerebral palsy, with complex communication needs and their interlocutors.

Methods: a propositional study type of a speech language and hearing science assessment tool whose methodological flowchart was divided into five phases.

Results: the final version of the protocol consisted of fifty-four items divided into three parts: (a) communicative means, acts of speech, topic maintenance and dialogue turn-taking, common to the dyads; (b) acts of child speech, use of resource, thematic maintenance and dialogue turn-taking and (c) speaker speech acts, encouragement of the use of the communication resource, theme maintenance and dialogue turn-taking. All assessment items receive a score by the assessment record according to presented linguistic behavior.

Conclusion: this study showed the development and creation of a conversation evaluation protocol for children with cerebral palsy and their interlocutors. It can be used to evaluate the means, the communicative acts and adjacent-pairs observed in conversational contexts, leading the initial clinical speech language and hearing assessment process to the introduction, maintenance and general use of the Augmentative and Alternative Communication with different interlocutors and environments.

Keywords: Speech, Language and Hearing Sciences; Communication; Child Language; Evaluation Studies;Cerebral Palsy

\section{RESUMO}

Objetivo: propor um protocolo para avaliaçãoda comunicação que contemple a análise conversacional de crianças com encefalopatia crônica não evolutiva com necessidades complexas de comunicação e seus interlocutores.

Métodos: estudo do tipo propositivo de um instrumento de avaliação fonoaudiológica, cujo fluxograma metodológico foi dividido em cinco fases.

Resultados: a versão final do protocolo é composta por 54 itens divididos em três partes: (a) meios comunicativos, atos de fala, manutenção temática e turno de diálogos comuns às díades; (b) atos de fala da criança, uso do recurso, manutenção temática e turno de diálogo e (c) atos de fala do interlocutor, incentivo ao uso do recurso comunicativo, manutenção temática e turno de diálogo. Todos os itens da avaliação recebem uma pontuação por registro de avaliação, conforme o comportamento linguístico apresentado.

Conclusão: o presente estudo apresentou o desenvolvimento e a criação de um protocolo de avaliação da conversação para crianças com encefalopatia crônica não evolutiva e seus interlocutores. Esse poderá ser utilizado para avaliar os meios, os atos comunicativos e os pares adjacentes observados em contexto conversacional, conduzindo o processo de avaliação fonoaudiológica inicial da linguagem para a introdução, manutenção e generalização do uso da Comunicação Suplementar e Alternativa com diferentes interlocutores e ambientes.

Descritores: Fonoaudiologia; Comunicação; Linguagem Infantil; Estudos de Avaliação; Paralisia Cerebral 


\section{INTRODUCTION}

The process of language evaluation and verbal understanding of children is a constant challenge for clinical speech language and hearing pathologists and / or researchers. In our country's literature the problem resulting from the scarcity of evaluations of children's language is a present theme. However, about children without neurological damage the publications of Brazilian researchers have increased in recent decades. Despite the need for greater availability of instruments ${ }^{1,2}$ for the evaluation of children's language, there are already several tools to evaluate different components of the language.

In the case of people with cerebral palsy (CP), the number of tools available in Brazil is even scarcer, increasing the difficulty of evaluating the communication of this population. With these children, global neuromotor abilities are impaired, and often a deficiency of the orofacial praxis is also observed, making expression difficult by typical means. In these cases the implementation of an Augmentative and Alternative Communication (AAC) ${ }^{3}$ system is indicated. We emphasize that the early implementation and in different contexts favors the generalization of the use of the AAC, as well as it supports orality, verbal comprehension, reading and writing ${ }^{4}$.

The assessment of verbal comprehension skills with children using AAC is fundamental, as it will determine the vocabulary that caregivers, teachers and others should use with them, as well as pointing out the need to intervene to increase word comprehension. Undoubtedly, these skills have important implications for AAC development.

Researchers ${ }^{5}$ from three studies selected words for evaluation of children and young people with complex communicational needs. The final list presents 269 items, classified into 18 semantic themes, instrumentalizing even more the speech language and hearing evaluation

In this field, still scarce in publications, we observe the investigation of the vocabulary of children with DownSyndrome, considering the mental age variable. The study concludes that these children presented expressive vocabulary shorter than expected for chronological age, but close to that expected for mental age ${ }^{6}$.

When it comes to children with complex communication needs, such as AAC users, language and other important aspects of language assessment become even more difficult, requiring specific elaboration or adaptation of existing tools. An example of this demand is observed in study which investigated the applicability of the assessment tools of children's language in the population with physical, hearing, visual, mental and multiple disabilities.

Although there is a growing awareness of aspects related to the use of AAC and its impact on the daily life of children and their interlocutors, the gap in literature in this area is evident when it comes to considering the conversational dialogic dimension that the AAC use requires. The existing tools do not allow a clearer picture of how dyads use AAC.

Due to the notorious impact that the daily interactions of the child have on the learning of this communicative environment, it is necessary to evaluate not only the communicative abilities of the child, but also the use of the AAC by its interlocutor. The communicative kills and abilities of the child and his / her main interlocutors are important elements to be considered in the speech-language therapy process. Speech-language pathologists, as well as other therapists and educators who, in a certain way, have role models for the family, do not have the means to evaluate their conversational practice with AAC patients. There is still a need to expand studies regarding evaluations that cover other conversational partners of children with $\mathrm{CP}$, with restricted or absent orality.

This type of evaluation could provide parameters that would reflect on the improvement of the professional services rendered, as well as to detect communication difficulties that could be solved by the interlocutors themselves. In this way, conversational assessments could undoubtedly produce important guidance material for the family and school.

The lack of studies of the conversational aspects generates a lack of criteria. In this sense, assisted evaluations are fundamental to better understand the potential of AAC users, favoring the development of programs based on individual needs ${ }^{8}$ and orientations to family members and other interlocutors ${ }^{9}$. The present study uses principles of discursive theory (segmental, supra-segmental elements, alternation of subject and dialogic turn, adjacent pairs, communicative unit, types of communicative means and speech acts) to support the evaluation of communication by the speech therapist in the area of AAC. It is noticed that the speech-language pathologist has the conditions, based on a greater theoretical appropriation and good practices, to favor the functional use of the AAC system, explicitly assuming their function of communication 
management towards a professional team in the AAC area.

Considering the above mentioned issues, this study aims to propose a speech-language assessment protocol that contemplates the conversational analysis of children with $\mathrm{CP}$, with complex communication needs and their interlocutors.

\section{METHODS}

It is a propositional study for the development and creation of a speech language and hearing science assessment tool for dialogical conversational analysis.

\section{Ethical Procedures}

This study complies with the norms of the Research Ethics Committee (CEP) of the Federal University of Santa Maria, according to number 909.685, the Certificate of Presentation for Ethical Presentation (CAAE) number 38137814.3.0000.5346, and it is in accordance with the norms of the Ministry of Health in accordance with 196/96 and 466/12 Resolution.

\section{Participants}

Two speech language and hearing science therapists participated in this study, according to their respective phases of study. One of them has had three years of clinical experience with AAC, and has completed her final course work on the subject. The other speech therapist is a researcher, with a doctorate in the field of conversational analysis of patients with neurological damage.

\section{Procedures}

\section{Phase 1}

The items of the protocol were generated from the data analysis of three children with CP and their dyads during 3 speech language and hearing services. The corpus was analyzed according to the fundamentals of the speech acts theory of Searle ${ }^{10}$ and Marcuschi ${ }^{11}$.

\section{Phase 2}

The filming was analyzed and revised eleven times by the first author to complete the categorization of speech acts and the communicative means of children using $A A C$ and their interlocutors with items considered relevant to understand the communicative profile of AAC users.

\section{Phase 3}

The list of selected items and the general list of speech acts were sent totwo speech language and hearing judges. The purpose of this phase was to examine the concordance of analysis regarding the selection of the items, as well as to collect suggestions from the judges on how to improve the tool.

The first analysis of the protocol pilot was carried out by the judges and, based on the contributions received, it was observed the need to carry out some reformulations, both of terms used and in the way of presenting the items (more descriptive and explanatory).

\section{Phase 4}

A second pilot protocol was developed and a second round of evaluation was conducted with the same judges, generating the final version of the evaluation protocol. The acceptable comparative parameter for concordance occurrences should be equal to or greater than $70 \%$, according to Fagundes ${ }^{12}$. In the second round of evaluation the index was $97 \%$.

\section{Phase 5}

At that stage, the final version of the protocol was composed of the following parts:

A) Communicative means of dyads;

B) Acts of speech of dyads;

C) Speech acts only of the child;

D) Speech acts only of the interlocutor.

Figure 1 represents the methodological flow of the protocol elaboration: 


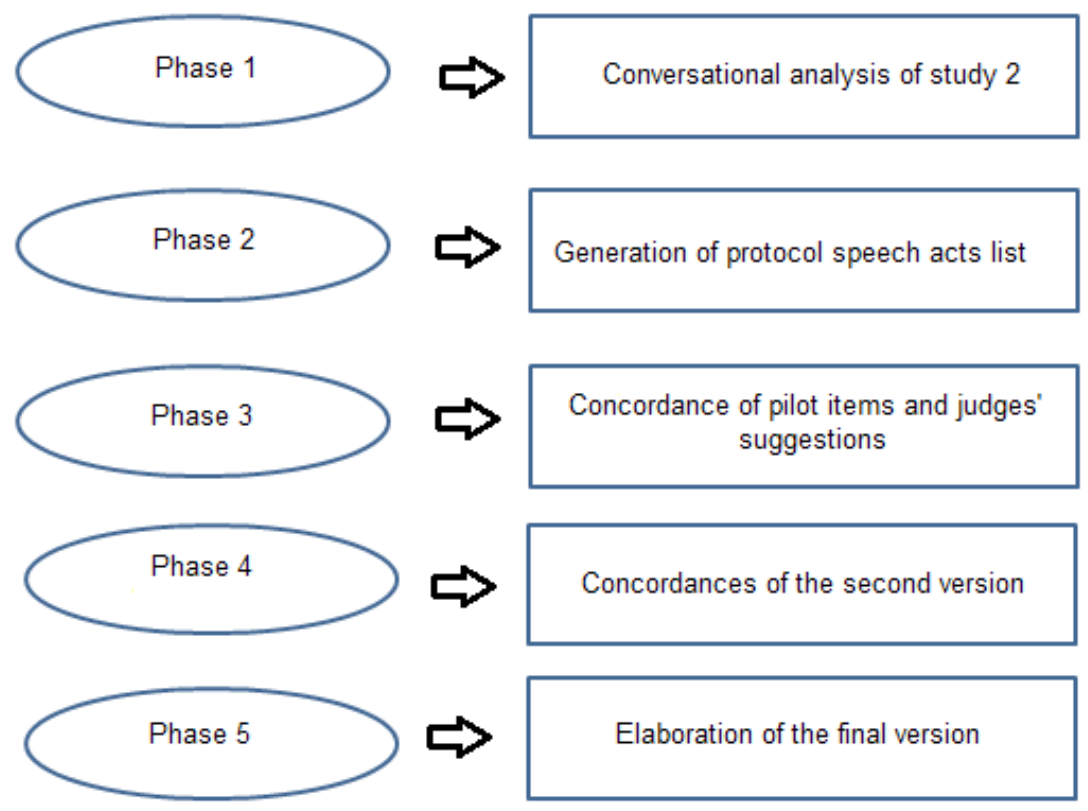

Figure 1. Methodological flow of protocol elaboration

\section{RESULTS}

The elaborated protocol aims to serve as a means of functional evaluation of the complementary communication linguistically. It is proposed to provide data on how the AAC child user and his /her interlocutor communicate in conversations in daily life. It is recommended that the recording of data should be done through the analysis offilms with ten minutes each of three speech-language sessions with different interlocutors. Filming should focus on the child's communicative activities with one or two relevant interlocutors.

The idea of requiring systematic observations is to avoid the risks of establishing early conclusions based on a single subjective assessment. It is suggested that the examiner should use, whenever possible, the comparison of his/her observations with the analysis performed by another experienced assessor in the use of AAC.

The protocol can be applied both in the therapeutic and educational context serving as a way to improve the work of professionals who attend patients who communicate via AAC. In the domestic context, it also serves as a way to identify, together with the parents, points that need guidance and characterize successful strategies already used.

The final version of the protocol presented in this section is composed of 54 items, divided into three parts: (a) communicative means, acts of speech, thematic maintenance and dialogue turn-taking, common to the dyads; (B) speech acts only of the child, use of the Augmentative and Alternative Communication resource, thematic maintenance and dialogue turn-taking, and (c) speech acts only of the interlocutor, encouragement to use the Augmentative and Alternative Communication resource, thematic maintenance and dialogue turn-taking.

Since the study has no normative data and was created from a predominantly qualitative study, a form of categorical and descriptive punctuation was provided, at least at this stage of the current protocol development. All items in the evaluation should receive a score in the form of a scale per evaluation day, according to the linguistic behavior presented, namely: not present, sometimes, frequently and always (Figure 2). 


\section{CONVERSATIONAL ANALYSIS OF DYADS PROTOCOL}

Name:

Date of birth :

Age:

\begin{tabular}{|c|c|c|c|c|}
\hline \multirow{2}{*}{ Register } & \multirow{2}{*}{ Date } & Collection & \multicolumn{2}{|c|}{ Interlocutors } \\
\cline { 4 - 5 } & time & & Name & \\
\hline $1^{\text {st }}$ day & & & & \\
\hline $2^{\text {nd }}$ day & & & & \\
\hline $3^{\text {rd }}$ day & & & & \\
\hline
\end{tabular}

ORIENTATION: note by registration day who the child's dyad was:

Dyads:

\begin{tabular}{|c|c|c|c|}
\hline (a) mother & (b) father & (c) siblings & (d) friend \\
\hline (e) speech therapist & (f)other therapists & (g) teacher & (h) other \\
\hline
\end{tabular}

ORIENTATION: note by registration day the score below for each item:

Score:
(0) not present
(1) sometimes
(2) frequently
(3) always

PART 1 - CONVERSATIONAL ANALYSIS OF THE COMMON ITEMS PRODUCED BY INTERLOCUTORS

Types and definitions of AAC means

\begin{tabular}{|c|c|l|}
\hline ACRONYMS & MEANS & \multicolumn{1}{|c|}{ DEFINITIONS } \\
\hline GE & Gestural & Expression with facial mime, movements and body gestures. \\
\hline VO & Vocal & $\begin{array}{l}\text { Non-articulated vocalization, smile, laughter, howling, screaming, groaning, crying, sighing } \\
\text { and / or sounding yawn. }\end{array}$ \\
\hline O & Oral & Speech emission partially and / or totally intelligible. \\
\hline OA & Orally Assisted & Expression with high technology AAC with sonorized emission of the resource. \\
\hline PIC & Pictorial & Expression with communication figures. \\
\hline
\end{tabular}

A) DYADS COMMUNICABLE MEANS

\begin{tabular}{|c|c|c|c|c|c|c|c|c|}
\hline \multirow{2}{*}{ Dyads } & \multicolumn{5}{|c|}{ Communicative means } & \multicolumn{3}{c|}{ Register } \\
\cline { 2 - 9 } & GE & V0 & 0 & OA & PIC & 1st & 2nd & 3rd \\
\hline Children & & & & & & & & \\
\hline Interlocutors & & & & & & & & \\
\hline
\end{tabular}

B) DYADS SPEECH ACTS

\begin{tabular}{|c|c|c|c|c|c|c|}
\hline \multirow{2}{*}{ Item } & \multirow{2}{*}{ Topic } & \multicolumn{2}{|c|}{ Dyads } & \multicolumn{3}{|c|}{ Register } \\
\hline & & C & I & 1st & 2nd & 3rd \\
\hline 1 & Request one object to another person & & & & & \\
\hline 2 & Request an action & & & & & \\
\hline 3 & Meetanobjectrequest & & & & & \\
\hline 4 & Meet a request for action & & & & & \\
\hline 5 & Protest against a situation and / or person & & & & & \\
\hline 6 & Can retaliate against the protest of the other & & & & & \\
\hline 7 & Name something & & & & & \\
\hline 8 & Produce questions to the other & & & & & \\
\hline 9 & Carry out the narrative & & & & & \\
\hline 10 & Produce an explanation about something and / or someone & & & & & \\
\hline
\end{tabular}


C) THEMATIC MAINTENANCE OF DYADS

\begin{tabular}{|c|l|c|c|c|c|c|}
\hline \multirow{2}{*}{ Item } & \multicolumn{1}{|c|}{ Topic } & \multicolumn{3}{c|}{ Dyads } & \multicolumn{3}{c|}{ Register } \\
\cline { 3 - 6 } & & C & I & 1st & 2nd & 3rd \\
\hline 1 & Can start a new topic (theme) & & & & & \\
\hline 2 & Can keep some subject during a conversation & & & & & \\
\hline
\end{tabular}

D) DYAD DIALOGUE TURN-TAKING

\begin{tabular}{|c|l|c|c|c|c|c|}
\hline \multirow{2}{*}{ Item } & \multicolumn{1}{|c|}{ Topic } & \multicolumn{2}{c|}{ Dyads } & \multicolumn{3}{c|}{ Register } \\
\cline { 4 - 6 } & & C & I & 1st & 2nd & 3rd \\
\hline 1 & Can wait his/her turn to speak & & & & & \\
\hline 2 & $\begin{array}{l}\text { Can pass the turn to speak by some communicative means (look or } \\
\text { gesture) }\end{array}$ & & & & \\
\hline 3 & $\begin{array}{l}\text { Can signal by some communicative means that one is attentive } \\
\text {-attention to what the other is saying }\end{array}$ & & & & \\
\hline 4 & $\begin{array}{l}\text { Accept the turn taking and communicate in some way that one will } \\
\text { occupy one's turn to speak }\end{array}$ & & & & \\
\hline
\end{tabular}

\section{PART 2 - CONVERSATIONAL ANALYSIS OF CHILDREN}

\section{A) SPEECH ACTS OF CHILDREN}

Subtypes of responses

\begin{tabular}{|c|c|c|c|c|}
\hline \multirow{2}{*}{ Item } & \multirow{2}{*}{ Topic } & \multicolumn{3}{|c|}{ Register } \\
\hline & & 1st & 2nd & 3rd \\
\hline 1 & $\begin{array}{l}\text { Respond correctly to a question that offers the "yes" or "no" as possibilities of answers via } \\
\text { AAC }\end{array}$ & & & \\
\hline 2 & Answer correctly a question that offers two other possibilities of answers presented via AAC & & & \\
\hline 3 & Correctly answer a question that offers more than two answer possibilities presented via AAC & & & \\
\hline 4 & Respond correctly to an open question via AAC & & & \\
\hline 5 & Respond correctly to a question that offers the "yes" or "no" verbally & & & \\
\hline 6 & Answer correctly a question that offers two other possibilities of answers presented verbally & & & \\
\hline 7 & $\begin{array}{l}\text { Answer correctly a question that offers more than two possibilities of answers presented } \\
\text { verbally }\end{array}$ & & & \\
\hline 8 & Respond correctly to an open question presented verbally & & & \\
\hline 9 & Produce an unintelligible response to an inquiry that offers the "yes" or "no" via AAC & & & \\
\hline 10 & $\begin{array}{l}\text { Produce an unintelligible answer to a question that offers two other possibilities of answers } \\
\text { presented via AAC }\end{array}$ & & & \\
\hline 11 & $\begin{array}{l}\text { Produce an unintelligible answer to a question that offers more than two possibilities of } \\
\text { answers presented via AAC }\end{array}$ & & & \\
\hline 10 & $\begin{array}{l}\text { Produce an unintelligible answer to a question that offers the "yes" or "no" as possibilities of } \\
\text { answers verbally }\end{array}$ & & & \\
\hline 11 & $\begin{array}{l}\text { Produce an unintelligible answer to a question that offers two other possibilities of answers } \\
\text { presented verbally }\end{array}$ & & & \\
\hline 12 & $\begin{array}{l}\text { Produce an unintelligible answer to a question that offers more than two possibilities of } \\
\text { answers presented verbally }\end{array}$ & & & \\
\hline 13 & Produce an unintelligible response to an open question presented verbally & & & \\
\hline
\end{tabular}


Subtypes of executions

\begin{tabular}{|c|l|c|c|c|}
\hline \multirow{2}{*}{ Item } & \multicolumn{1}{|c|}{ Topic } & \multicolumn{3}{|c|}{ Register } \\
\cline { 3 - 5 } & & 1st & 2nd & 3rd \\
\hline 1 & Meetanobjectrequest & & & \\
\hline 2 & Meet a request for symbolic action & & & \\
\hline
\end{tabular}

B) AAC RESOURCE USE

\begin{tabular}{|c|l|c|c|c|}
\hline \multirow{2}{*}{ Item } & \multicolumn{1}{|c|}{ Topic } & \multicolumn{3}{|c|}{ Register } \\
\cline { 3 - 5 } & Meet a specific action request related to communicative resource management & & & 2nd \\
\hline 1 &
\end{tabular}

C) THEMATIC MAINTENANCE

\begin{tabular}{|c|l|c|c|c|}
\hline \multirow{2}{*}{ Item } & \multirow{2}{*}{ Topic } & \multicolumn{3}{|c|}{ Register } \\
\cline { 3 - 5 } & & 1st & 2nd & 3rd \\
\hline 1 & Turn-taking in conversation & & & \\
\hline
\end{tabular}

D) DIALOGUE TURN-TAKING

\begin{tabular}{|c|l|c|c|c|}
\hline \multirow{2}{*}{ Item } & \multicolumn{1}{|c|}{ Topic } & \multicolumn{3}{|c|}{ Register } \\
\cline { 3 - 5 } & & 1st & 2nd & 3rd \\
\hline 1 & Take a turn to look at the AAC resource something one wants to communicate & & & \\
\hline
\end{tabular}

PART 3 - CONVERSATIONAL ANALYSIS OF INTERLOCUTORS

A) TALKING ATTRIBUTES OF THE INTERLOCUTOR Inquiries

\begin{tabular}{|c|l|c|c|c|}
\hline \multirow{2}{*}{ Item } & \multicolumn{1}{|c|}{ Topic } & \multicolumn{2}{|c|}{ Register } \\
\cline { 3 - 5 } & \multicolumn{1}{|c|}{ 1st } & 2nd & 3rd \\
\hline 1 & $\begin{array}{l}\text { Produce a question that verbally offers "yes" and "no" as alternative answers and / or also } \\
\text { produce a question that subtends the possibilities of "yes" and "no" as a response to the child }\end{array}$ & & \\
\hline 2 & Produce a question that offers two possibilities for answers other than the "yes" or "no" & & & \\
\hline 3 & $\begin{array}{l}\text { Produce a question that offers more than two possibilities of answers other than the "yes" or } \\
\text { "no" }\end{array}$ & & \\
\hline 4 & Produce an open question & & & \\
\hline
\end{tabular}

Subtypes of responses

\begin{tabular}{|c|l|c|c|c|}
\hline \multirow{2}{*}{ Item } & \multicolumn{1}{|c|}{ Topic } & \multicolumn{3}{|c|}{ Register } \\
\hline 1 & Respond to the child & & 2st & 3rd \\
\hline 2 & Respond to the child without giving a minimum of 10 seconds to his /her response & & & \\
\hline 3 & Respond to the child after giving a minimum of 10 seconds to his/her response & & & \\
\hline
\end{tabular}

Auxiliary speech acts and incentives

\begin{tabular}{|c|c|c|c|c|}
\hline \multirow{2}{*}{ Item } & \multirow{2}{*}{ Topic } & \multicolumn{3}{|c|}{ Register } \\
\hline & & 1st & 2nd & 3rd \\
\hline 1 & Praise the child to herself and / or to family members and / or other present interlocutors & & & \\
\hline 2 & Encourage the child to communicate & & & \\
\hline 3 & Correct the child when he/she offers a wrong response or action. & & & \\
\hline 4 & Call the child's attention to the conversation & & & \\
\hline 5 & Confirm the child's response by repeating the same response the child expressed & & & \\
\hline
\end{tabular}


B) INCENTIVE TO THE AAC RESOURCE USE

\begin{tabular}{|c|l|c|c|c|}
\hline \multirow{2}{*}{ Item } & \multicolumn{1}{|c|}{ Topic } & \multicolumn{1}{|c|}{ Register } \\
\cline { 3 - 4 } & & \multicolumn{1}{|c|}{ 1st } & 2nd & 3rd \\
\hline 1 & $\begin{array}{l}\text { Point to and shows the symbol being referred to in the AAC. In the high tech feature press the } \\
\text { button that contains the symbol and then the device vocalizes. }\end{array}$ & & \\
\hline 2 & Provide motor assistance for the child to use the AAC resource & & & \\
\hline 3 & Make corrections to using the AAC feature & & \\
\hline 4 & Can direct the child's attention so that she/he communicates her response using the AAC & & \\
\hline 5 & Encourage the child to use the AAC & & \\
\hline
\end{tabular}

C) THEMATIC MAINTENANCE

\begin{tabular}{|c|l|c|c|c|}
\hline \multirow{2}{*}{ Item } & \multicolumn{1}{|c|}{ Topic } & \multicolumn{3}{|c|}{ Register } \\
\cline { 3 - 5 } & \multicolumn{1}{|c|}{ 1st } & 2nd & 3rd \\
\hline 1 & Favor the child's engagement in the conversation to return to the topic & & & \\
\hline
\end{tabular}

D) DIALOGUE TURN-TAKING

\begin{tabular}{|c|l|c|c|c|}
\hline \multirow{2}{*}{ Item } & \multicolumn{1}{|c|}{ Topic } & \multicolumn{3}{|c|}{ Register } \\
\cline { 3 - 5 } & & 1st & 2nd & 3rd \\
\hline 1 & Provide opportunities for the child to initiate a new dialogue turn-taking & & & \\
\hline
\end{tabular}

C: children; AAC: Augmentative and Alternative Communication; I: interlocutor

Figure 2. Protocol

\section{DISCUSSION}

The functional communication evaluation tool developed in this study is the result of a construction process elaborated from the naturalistic conversation of children with $\mathrm{CP}$ and their different conversational partners during speech therapy sessions, generating categories of analysis justified by the language in use.

The proposition here does not exclude the importance of using other tools, such as those that evaluate other important dimensions of language and cognition, emphasizing that verbal comprehension skills have great clinical and educational implications for the development of children that make use of AAC.

The use of this protocol in the speech language and hearing clinic favors the detection of the functional linguistic profile of both the child and his / her interlocutors, that is, it is an evaluation that presents adualfocus in a naturalistic environment, and it can also serve as a way to follow the development of the use of the AAC, when used as the initial evaluation and later as a periodic evaluation. The use of research using elements of pragmatics with AAC in naturalistic environment is also reported in a case study ${ }^{8}$ of a child with autism spectrum disorder and his/her teacher.
Researchers ${ }^{13}$ used the Behavioral Observation Protocol (PROC) to evaluate fourteen children with neurological lesions and with severe communication impairments. The study ${ }^{13}$ indicates the possibility of using PROC in the population with neurological lesions and severe communicative impairment, but they recommend to associate other process evaluation tools and measures.

The proposed protocol can be used in different moments of the speech language and hearing therapy process to investigate how the process of maintaining AAC use in the session is and especially to measure the generalization of the use of AAC to different environments besides the clinical one. It aims at favoring the increase of the quality of life of the child and the family.

Thus, the speech therapist can develop therapeutic programs that contribute to the development of the use of AAC in a multimodal system view and not only based on an operation that is limited to selecting figures and technological resources ${ }^{14}$.

Therefore, consideration should be given to the complementary use of other assessments and to the adequate interpretation of the data of this protocol in order to obtain important information about competence and linguistic and communicative skills ${ }^{14-16}$. 
Such information will support the provision of a model of multiple communication rather than one centered on the oral language mode ${ }^{16}$ by the speech therapist and other interlocutors of the child, especially the most significant ones. Its main goal is the development of the language of children with complex communication needs.

\section{CONCLUSION}

The present article presented the development and creation of a conversation evaluation protocol for children with $\mathrm{CP}$ and their interlocutors. This study can be used to evaluate the means, conversational acts and adjacent pairs produced from the acts, leading the process of speech language assessment for the introduction, maintenance and generalization of the use of AAC with different interlocutors and in different contexts. Future research is necessary for the standardization and validation of the tool proposed by the study.

\section{REFERENCES}

1. Hage SRV, Pereira TC, Zorzi JL. Behavioral Observation Protocol: reference values for a quantitative analysis. Rev. CEFAC. 2012;14(4): 677-90.

2. Bento-Gaz ACP, Befi-Lopes DM. Adaptação do teste Clinical Evaluation of Language Functions - $4^{\text {th }}$ Edition for Brazilian Portuguese. CoDAS. 2014;26(2):131-7.

3. Cesa CC, Kessler TM. Comunicação alternativa: teoria e prática clínica. Distúrb.Comun. 2014;26(3):493-502.

4. Cesa CC, Mota HB. Augmentative and alternative communication: scene of Brazilian journal. Rev. CEFAC. 2015;17(1):264-69.

5. Paura AC, Deliberato D. Estudo de vocábulos para avaliação de crianças com deficiência sem linguagem oral. Rev. Bras. Ed. Esp. 2014;20(1):37-52.

6. Ferreira-Vasques AT, Abramides DVM, Lamônica DAC. Mental age in the evaluation of the expressive vocabulary of children with Down Syndrome. Rev. CEFAC. 2017;19(2):253-9.

7. Guimarães CF, Oda AL. Child language assessment tools: applicability to handicapped. Rev. CEFAC. 2013;15(6):1690-702.

8. Gomes RC, Nunes DRP. Interações comunicativas entre uma professora e um aluno com autismo na escola comum: uma proposta de intervenção. Educ. Pesqui. 2014;40(1):143-61.

9. Deliberato D, Massaro M, Goldoni NI, Silveira JMV. Programa de capacitação de famílias de crianças, jovens e adultos usuários de comunicação alternativa. Informática na Educação. 2013;16:89-102.

10. Searle JR. Os actos de fala: um ensaio de filosofia da linguagem. Coimbra: Almedina; 1981.

11. Marcuschi LA. Análise da conversação. 6a.ed. São Paulo: Ática; 2007.

12. Fagundes AJFM. Descrição, definição e registro de comportamento. 17a ed. São Paulo: EDICON; 2015.

13. Tenor AC, Deliberato D. Análise do uso de instrumento de avaliação para crianças usuárias de comunicação alternativa. VII Encontro da Associação Brasileira de Pesquisadores em Educação Especial. Londrina 08 a 10 denov 2011 p. 1704-11.

14. Light J, McNaughton D. Putting people first: Re-thinking the role of technology in Augmentative and Alternative Communication intervention. Augment Altern Commun. 2013;29(4):299-309.

15. Light J, McNaughton D. Communicative Competence for Individuals who require Augmentative and Alternative Communication: a new definition for a new era of communication? Augment Altern Commun. 2014;30(1):1-18.

16. Deliberato $D$. Sistemas gráficos na comunicação alternativa: aquisição da competência comunicativa. In: Passerino LM, Bez MR, Pereira ACC e Peres A. (eds.)Comunicar para incluir. Porto Alegre: CRBF; 2013. p. 425-35. 